\title{
Investigations of Particle-Initiated Insulation Breakdowns in Bearings
}

\author{
Abhishek Joshi (iD) and Jörgen Blennow \\ Chalmers University of Technology, Department of Materials and Manufacturing Technology, Division of High Voltage Engineering, \\ Gothenburg SE-412 96, Sweden \\ Correspondence should be addressed to Abhishek Joshi; a.joshi@live.com
}

Received 14 April 2019; Revised 17 August 2019; Accepted 19 September 2019; Published 17 December 2019

Academic Editor: Shuhui Li

Copyright (c) 2019 Abhishek Joshi and Jörgen Blennow. This is an open access article distributed under the Creative Commons Attribution License, which permits unrestricted use, distribution, and reproduction in any medium, provided the original work is properly cited.

\begin{abstract}
Early failures in bearings of wind turbine drivetrains have increased after introduction of power electronic switches, which leads to shaft voltages and bearing currents. In presence of voltage, a rupture of bearing insulation could occur due to several plausible electro-physical mechanisms viz., asperities, electric breakdowns, particles, etc. The flow of high amperage current through the bearing during a breakdown mechanism could lead to early failures. Our aim is to understand the electrical behaviour of a bearing and elaborate by an equivalent electric circuit model, emphasizing on particle-initiated breakdowns. In presence of a shaft voltage, the particles form a path of low resistance through the bearing and results in flow of shaft or bearing currents, which could cause pre-mature failure of the bearing. Particles such as Arizona Test Dust (ATD), carbon black, aluminium powder and fine iron powder were mixed in lubricant at particle concentrations ranging between $7.5 \mathrm{mg} / \mathrm{L}$ and $150 \mathrm{mg} / \mathrm{L}$. The breakdown characteristics of electrical insulation of the bearing during a given test is quantified as time of conduction, which is expressed as a percentage of the time the bearing is in the conducting state during a test. An investigation of time of conduction for different lubricant samples was conducted along with studying the effects of start and stops of the rotating shaft. The electrical conductive nature of the particle played no role in breakdown of bearing voltage. At a fixed concentration of $150 \mathrm{mg} / \mathrm{L}$, the insulation breakdown events were highest in lubricant with ATD, followed by iron powder, aluminium power and carbon black particles. The time of conduction increases up to 24 times for the same test lubricant, as the particle concentration was increased from $7.5 \mathrm{mg} / \mathrm{L}$ to $150 \mathrm{mg} / \mathrm{L}$. The current activity reduced to almost half in the test after stopping the shaft rotation. The resistance of bearing during insulation breakdown events is highest for aluminium powder, followed by fine iron powder, carbon black and ATD.
\end{abstract}

\section{Introduction}

Failure analyses of electrical machines have revealed that prematurely failed bearings have been the leading cause for downtimes not only in wind power generation industry $[1,2]$, but also petroleum and chemical industries [3-5]. The high failure rate in bearings also result in large downtimes, which increases costs and reduces feasibility of energy generated from wind turbines. Thus, higher reliability of bearings is important, and their pre-mature failures should be reduced. These pre-mature failures have already been linked to the presence of additional electrical stress in the form of stray bearing currents and voltage across the bearing [6]. The stray bearing currents are commonly classified as: (i) Capacitive bearing currents [7-12], (ii) Capacitive discharge currents also popularly knowns as
Electrostatic Discharge Machining (EDM) type of bearing currents [7, 13-17], (iii) High Frequency (HF) circulating type of bearing currents $[7,11,12,18-20]$, (iv) HF ground currents $[7,21]$, and (v) Ohmic currents $[7,22]$.

At speeds higher than few 100's of rpm, the bearing rolls over a thin film of lubricant that bears the load of operation. Since the lubricating film formed around the rolling element is electrically insulating in nature, the bearing could withstand certain voltage across its inner and outer raceways; commonly referred to as bearing voltage. If the bearing voltage exceeds a certain threshold value, a path of low resistance is formed between the bearing raceways and could lead to a flow of high amperage bearing currents. The source of voltage in this case is caused by charging of stray capacitance within the machine due to the common mode voltage source and causes 


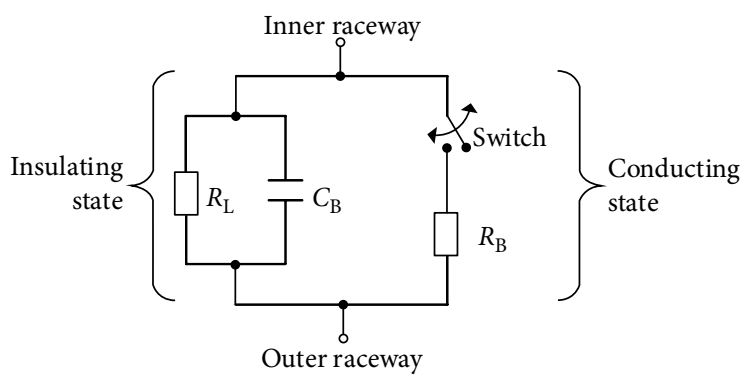

FIGURE 1: Equivalent electrical circuit model of a steel bearing. The left branch shows the insulating state; the right branch shows the conducting state.

capacitive discharge currents. Presence of particles and debris reduces the threshold voltage for causing breakdown events in the bearing. The flow of higher amperage HF circulating types of bearing currents through the bearing initiated due to the presence of particles is commonly found in larger machines and is known to cause premature failures in bearings [7]. The introduction consists of three parts; (1) proposed equivalent electrical circuit model of bearing, (2) plausible mechanisms leading to electrical breakdown in bearings, and (3) electrical circuit models of bearings reported in literature.

1.1. Equivalent Electrical Circuit Model of Bearings. The overall goal of our research is to increase the understanding of how bearing currents are initiated in a steel bearing in presence of electrical voltage, from an electro-physical perspective. In addition, investigating the electrical properties of bearings at different operating points is also a part of the overall goal. To fulfil this, we have proposed an equivalent electrical circuit model of the bearing based on its electrical behaviour as a function of different operating points. Thus, the bearing is electrically modelled as a system of several electrical component with two main electrical states, insulating and conducting. The components of these two electrical states are investigated as a function of operating points. The equivalent circuit model is presented in Figure 1, while similar electrical circuit models have also been reported in $[13,23]$. In this paper, we have experimentally investigated the electrical behaviour and properties of a miniature bearing with focus on particleinitiated breakdowns, i.e., findings limited to the conducting state properties under influence of particle-initiated electrical breakdowns are reported.

In the insulating state, as the bearing operates in EHL regime, the bearing can be represented by a parallel connection of a capacitance, $C_{\mathrm{B}}$, and a resistance, $R_{\mathrm{L}}$. The capacitance is determined by the bearing size and geometry as well as the relative permittivity of the lubricant. Thus, the $C_{\mathrm{B}}$ can change due to temporary changes in the physical, chemical or electrical properties of the film during operation and an elastic deformation in bearing. The bearing current driven by common mode voltage then mainly flows capacitively through the bearing in insulating state. In parallel to the capacitance, a resistance, $R_{\mathrm{L}}$, is connected, representing all kind of losses in the lubricant, such as conductive losses but also possible polarization losses of components inside a bearing. The lubricant film thickness is generally in the order of $0.2-2 \mu \mathrm{m}$ [24], and changes with the bearing type.

In conducting state, a breakdown mechanism forms a low resistive path, electrically bridging bearing raceways, which represents a temporary closing of the switch of the electrical circuit shown in Figure 1. In the event of a breakdown, the resistance of the bearing in conducting state is much lower than impedance in insulating state. The total current will consist of two components, a capacitively driven current through the machine stray capacitances and a discharge current due to discharge of the machine stray capacitances. Bearing resistance, $R_{\mathrm{B}}$ is given by the ratio of the measured bearing voltage and bearing current.

The lubricating film thickness during operation is in the range of $0.2-2 \mu \mathrm{m}$ in a running bearing. A voltage of few 10 's of volts [6] thus results in high electric fields (up to $100 \mathrm{~V} / \mu \mathrm{m}$ ) in the sub-micron lubricating film, and an insulation breakdown of the film results in heating, evaporation of lubricant, melting of bearing steel and crater formation on bearing surfaces.

To obtain a resistively flowing current through the bearing, two conditions must be fulfilled: (i) a breakdown mechanism that provides a temporary electrical path through the insulating bearing lubricant and, (ii) a shaft voltage that drives a current through the path established. When this occurs, the voltage across the bearing, i.e., the bearing voltage, drops to a small value, determined by the resistance of the conducting path $\left(R_{\mathrm{B}}\right)$.

\subsection{Electrical Breakdowns Mechanisms inside Bearing. A} breakdown event inside the bearing provides a low impedance path for the flow of bearing currents, leading to its premature failure. Different types of bearing currents can flow through the bearing during the breakdown of electrical insulation of the bearing. An insulation breakdown could occur inside the bearing due to several plausible mechanisms such as, (i) asperity contacts, (ii) electrical breakdown of lubricating film, and (iii) contamination and solid particles.

Frequent asperity contacts during bearing operation leads to discharge of any bearing voltage present between the inner and outer raceways of the bearing. The asperities (local peaks) on the metallic surfaces of the raceways and rolling element make frequent physical contacts to provide a path for flow of ohmic current through the bearing. Frequent asperity contacts are present at low rotational speeds, but are not influential at higher rotational speeds because an oil film separates the interacting surfaces inside the bearing.

Electrical breakdown of the lubricating film also leads to formation of conducting path between the inner and outer raceways of the bearing and occurs when the bearing voltage crosses a threshold [7, 13-17]. The breakdown phenomenon could also be treated similar to electric breakdown of insulating oils [25-31]. This assumption should be taken with precaution since a higher load of operation (in order of 100's of $\mathrm{MPa}$ to a few $\mathrm{GPa}$ ) on the liquid lubricating film in the bearing results in a glassy state of the lubricant, where the lubricant does not have liquid-like properties [32-34].

Contaminants and solid particles are part of the lubrication in case of presence of external particles, or solid particles 
eroded off the bearing surfaces [35-43]. The effect of different particle types, sizes and concentration levels are studied by investigating current activity and number of breakdowns in bearing. The paper also aims to find differences in conduction properties of different particles, along with study of bearing resistance $\left(R_{\mathrm{B}}\right)$ during discharges. In a controlled laboratory environment, this study thus provides an analysis of breakdown of bearing voltage under current limiting conditions to avoid damages on bearing surfaces and to reuse test objects.

In field conditions, since an external HF source is driving the bearing currents, damages could occur on the bearing. Due to very small contact area, a breakdown will result in high current densities thus causing localized heating, melting damages and crater formation as well as re-hardening and brittling of surfaces. Discharge of energy stored in stray capacitances and the passage of current through the bearing can result in formation of micro-pits on the surfaces of the rolling elements and the raceways. The balls get a matte finish while the inner and the outer raceways develop an electrical fluting damage (or wash-boarding). It is evident from the morphology of the corroded surfaces that the micro-pits and corrugation pattern occur due to presence of an electrical stress during normal bearing operation as supported by [23, $24,44,45]$. It is also reported that the time for the bearing to develop corrugation pattern prematurely, logarithmically follows the apparent current density of the electrical current [46]. Presence of particles result in scratches, indentations on bearing surfaces. The load of the operation could also result in embedding of foreign particles in the bearing raceways. Since ample investigations have already been done on this subject $[23,24,44,45]$. Study related to the emergence of current initiated damage on surfaces of test bearings is thus not a scope of this publication.

In the industry, a bearing type is selected based on the operational conditions of the machine such as the operational speed and the radial and axial loading expected during operation. Nevertheless, the geometry of different types of bearings, i.e., point contact (e.g., ball bearing) or line contact (e.g., spherical bearing) will result in different contact and interacting profiles of the metallic surfaces. The breakdown of lubricant (bearing insulation) in the contact zone is thus influenced due to this geometric differences. Experimental investigations have shown that the breakdown field strength of bearing having line contact is found to be lower than that of point contact [47]. This is because for a same size of bearing, a bearing with line contact has more Hertzian contact area and thus higher chances of initiating a current path than a bearing with point contact.

1.3. Electrical Circuit Models of Bearing in Literature. The electrical circuit modelling found in literature is also based on similar line of thought. The focus was largely kept in modelling of the stray capacitances in the common mode equivalent circuit. In a simple version of the common-mode circuit model proposed by Busse et al. in [48], the bearing model forms a part of the common-mode equivalent circuit model along with the converter and the machine. The bearing model is represented by the capacitance $C_{\mathrm{b}}$, a nonlinear impedance $Z_{1}$ and bearing resistance during the event of an electrical discharge $\left(R_{\mathrm{b}}\right)$,

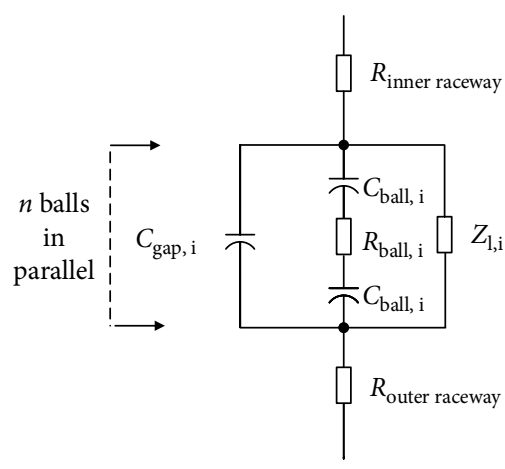

Per ball model

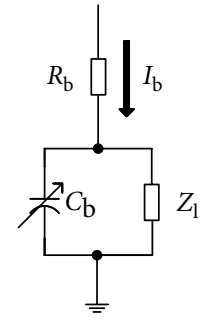

Reduced model
FIGURE 2: Ball per ball and reduced model of the mechanical bearing, adopted from [41].

shown in Figure 2. $C_{\mathrm{b}}$ is shown to be variable since the bearing capacitance is a function of electrical properties of lubricant and the geometric separation between the tribological parts. The authors describe the non-linear device to represent the charging and discharging of the shaft, i.e., in other words, the occurrence of electrical breakdown events in the bearing. The authors propose that the metallic bearing elements such as raceways and rollers represent resistances which are having effective resistances $R_{\text {inner raceway }}, R_{\text {outer raceway }}$ and $R_{\text {ball, } \mathrm{i}}$ respectively. Each roller is having a layer of lubricating film around itself, which is represented by $C_{\text {ball,i, }}$, which forms near the inner and outer raceway respectively. This forms of an effective capacitance $C_{\text {gap, }}$ between each set of balls, which results in " $n$ " parallel capacitors. Furthermore, $Z_{1}$ is added to the model to account for abnormal mechanical and electrical occurrences in the bearing. The nature of breakdown of the voltage across the bearing is termed a statistical and is dependent on the collapse of $Z_{\mathrm{l}}$, which is to be determined through experiments. This breakdown of the bearing is hence said to be dependent on the position of the ball along with the condition of bearing surfaces and the lubricant's electrical characteristics.

At higher speeds, the film is formed and the impedance of the bearing $\left(Z_{1}\right)$ is higher, reported to be in megaohm range. As the focus of majority of the studies has been kept on system level parameters and the emergence of different kinds of bearing currents, more emphasis can be given to elaborate the mechanisms with which the electrical breakdown events occur in the bearing. The motion of the bearing is complicated due to its dynamic nature and the variable nature of mechanical and electrical stresses and thus needs further elaboration. In the literature, the breakdown of bearing is also portrayed by a switch, but with arbitrarily chosen time of breakdown $[7,11]$. The breakdown characteristics of lubricating film of bearing depend on many factors such as motion, magnitude of voltage across it, surface roughness of bearing, vibration levels, lubricant film properties, oil cleanliness among others.

To further the understanding of behavior of bearing during conducting state, rather recent experimental investigations [19] are reported on the nonsteady nature of electrical breakdown events of bearing under the influence of discharge bearing currents and HF voltage. The model proposed is on 


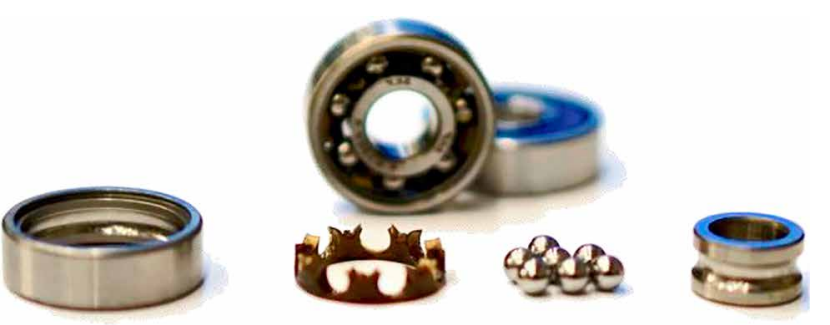

Figure 3: Bearing 608 disassembled into its components. From left to right, outer raceway, cage, balls and inner raceway. Assembled bearings are shown in the background.

similar lines as the one proposed in this publication. The transition of the bearing from capacitive state (no breakdown) to ohmic state (breakdown) is dependent on the certain operating points such as speed and load, which the authors have termed as "Transition Activity, TRA". In conclusion to their work, the general outcome was that the transition activity in bearing increases with an increase in temperature and the amplitude of the applied voltage. Bearing stays longer in resistive mode at lower speed, while it stays longer in capacitive mode at speed. Although, it is stated that the current conduction and breakdown mechanisms in rolling element bearings are only partially understood now.

\section{Methods}

This section details the description of the test objects, test bench, and the electrical circuit in which the bearing under test is connected. An overview of the analyses methods and the measurement are discussed in this section.

2.1. Test Objects and Test Setup. For the experiments, deep groove steel ball bearings of type SKF 608 with seven balls was used, shown in Figure 3. The outer diameter is $22 \mathrm{~mm}$ and the bore diameter is $8 \mathrm{~mm}$. It is a miniature ball bearing and has high limiting speed of 48,000 revolutions per minute (rpm). The static load rating is $1.37 \mathrm{kN}$ and the dynamic load rating is $3.45 \mathrm{kN}$. Cages made of Polyamide 6,6 separate the balls within the bearing. The test lubricant is composed of hydrotreated mineral type base oil blended with acrylic copolymer additives. The base oil viscosity is $100 \mathrm{~mm}^{2} / \mathrm{s}$ at $40^{\circ} \mathrm{C}$ and $11.4 \mathrm{~mm}^{2} / \mathrm{s}$ at $100^{\circ} \mathrm{C}$ [49]. The bearing is lubricated using an oil bath, with a level of $3 \mathrm{~mm}$.

For the experiments, four test bearings were prepared after a running-in process of virgin bearings lubricated with particle-free oil sample for 4 hours, and a separate bearing was used for a given type of particle.

The lubricants used in experiments are shown below along with the particle type, concentration level and the size class of the particles. The highest particle concentration was chosen to be at $150 \mathrm{mg} / \mathrm{L}$, since it is suggested to be the threshold of particle contamination by Elforsk in [35], a report on oil cleanliness in wind turbine gearboxes. Four different particles were used to prepare four versions of test lubricant, shown in Table 1. For Samples A1 and A2, five concentration levels ranging from $150 \mathrm{mg} / \mathrm{L}$ to $7.5 \mathrm{mg} / \mathrm{L}$ were prepared.
Samples A3 and A4 were tested at a concentration level of $150 \mathrm{mg} / \mathrm{L}$.

ATD comprises majorly of oxides of silicon $\left(\mathrm{SiO}_{2}-68 \%\right)$ and aluminium $\left(\mathrm{Al}_{2} \mathrm{O}_{3}-10 \%\right)$. Other smaller fractions include oxides of iron, sodium, calcium, and magnesium. Carbon black particles are taken from copy toner cartridge, and have a very small size (majority of the particles are smaller than $5 \mu \mathrm{m})$. Thus, there is a possibility that they cannot instantaneously bridge the gap at the inner and the outer raceways. Carbon black particles can hold electrical charge at the surface, and could thus coagulate on air bubbles in the lubricant. Aluminium and iron particles are chosen since they are electrically conducting in nature, thus they simulate electrically conducting properties of the bearing wear debris.

The bearing under test is mounted on a horizontal shaft together with a hybrid bearing, SKF hybrid bearing 608, with ceramic balls, shown in Figure 4. In this way, we have control over the current and discharge path through the bearing under test. The shaft is brought into rotation through a belt wheel and an insulating belt driven by a permanent magnet motor. A grounded U-girder, electrically insulated from the bearing housing, provides a solid foundation to the setup. Various levels of mechanical load can be applied by changing the position of the block. The axial load can be varied between 4 and $40 \mathrm{~N}$ [45]. The radial load is approximately $1 \mathrm{~N}$ on each bearing due to the weight of the shaft. The test bearing is axially loaded, which results in equal loading on all the balls in the bearing. The radial load slightly increases the load on the balls in the lower part of the bearing, due to weight of the shaft.

2.2. Cleaning Procedure. For the tests, the bearings were disassembled, and the surfaces were cleaned with isopropanol (99.9\% pure), followed by use of sonication process of the parts of the bearing and the bearing housing unit for 5 minutes. The bearing was reassembled in a clean environment using rubber gloves to avoid the transfer of impurities from hands to the bearing surfaces. The assembled bearing and the housing were the dried using a heat gun at $50^{\circ} \mathrm{C}$ for 10 seconds to remove the residual isopropanol from the surfaces. After the cleaning procedure, the bearing housing and the bearing were remounted on the test rig, followed by lubrication with a given type of lubricant sample, shown in Table 1. The cleaning procedures were repeated in same manner before testing at a given concentration level. The sonication process helped in removal of small particles from the raceways and the housing that could not be wiped out with isopropanol.

2.3. Evaluation Methods. The bearing was operated at room temperature and in laboratory environment and was run for 5 minutes before any types of measurements were performed. The speed was set at $2000 \mathrm{rpm}$, corresponding to a speed factor of 30000 (given by product of rotational speed and bearing mean diameter of $15 \mathrm{~mm}$ for bearing type SKF 608), while the axial load is $4 \mathrm{~N}$. Since the paper discusses the switching pattern analysis of the bearing during the conducting state, relevant evaluation methods are presented in this section.

The conducting state properties of a running bearing, i.e. characteristics of the switch and the bearing resistance $R_{\mathrm{B}}$, were evaluated by measuring the bearing voltage and the responding 

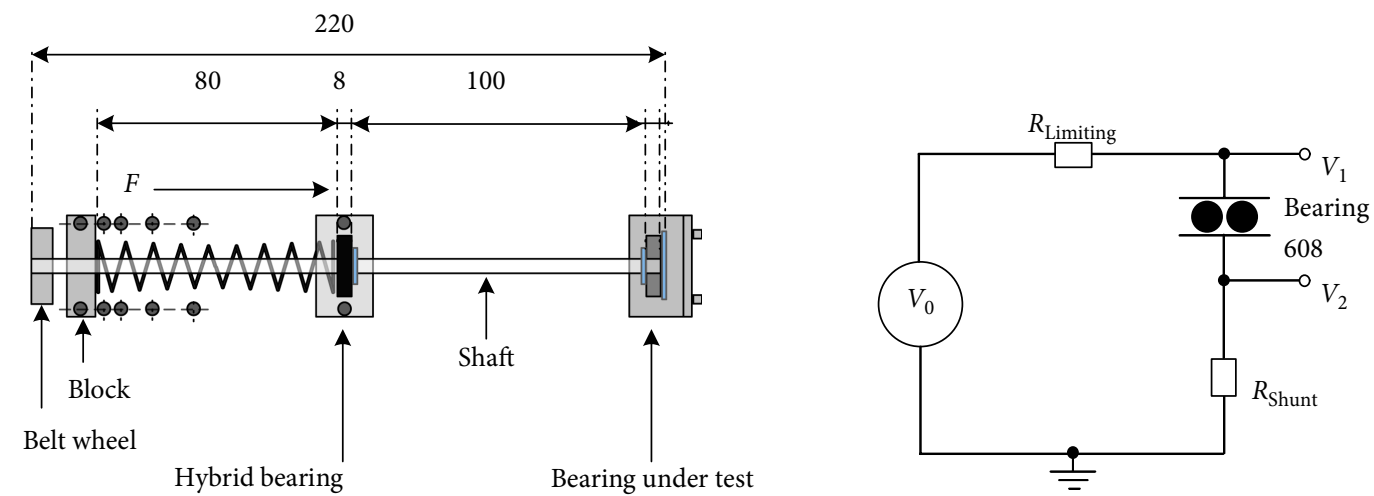

Figure 4: Test bench used for laboratory experiments. All measures in mm. The bearing is connected in an electrical circuit, where $V_{0}$ is the applied voltage. Bearing voltage is given by $V_{1}-V_{2}$ and the current through the bearing is given by $V_{2} / R_{\text {Shunt }}$.

current through the bearing when a DC voltage was applied. In this study, the focus is on particle-initiated breakdowns, thus operating points were selected so that no breakdowns result due to asperity point contacts. A DC voltage of $5 \mathrm{~V}$ does not cause breakdown in the bearing, and are discussed in detail in reference measurements in results. As particle-initiated bridges are made between the inner and outer raceway of the bearing, the switch in the electrical circuit model closes and represents a making of a temporary conducting path for a flow of current.

The reason for using a DC voltage was to ensure that a bearing voltage was present always which enables the detection of a sudden bridging conductive path through the lubricant as a current. The test voltage, $5 \mathrm{~V} \mathrm{DC}$, was supplied from a stabilized DC power supply (CE-BIT LK 31) to the shaft by means of a slip ring contact though a current limiting resistance $\left(R_{\text {Limiting }}=998 \Omega\right)$ to avoid possible current induced damages on the bearing surfaces, test circuit shown in Figure 4 . The bearing voltage $\left(V_{\mathrm{B}}\right)$ is equal to $V_{0}-V_{1}$. The current through bearing is measured as a voltage across a resistive shunt $\left(R_{\text {Shunt }}=82.7 \pm 0.5 \Omega\right)$; and is equal to $V_{2} / R_{\text {Shunt }}$. The resistors was chosen so that the current pulses recorded clearly can be distinguished from the noise level of $0.01 \mathrm{~mA}$, hence a threshold of $0.1 \mathrm{~mA}$ was chosen to exclude effects from noise.

The insulation breakdown of the bearing was characterized with respect to different speeds and mechanical loads during operation. The bearing current activity due to particle-initiated breakdowns is quantified by the percentage time of conduction (ToC) during a measurement. ToC is the fraction of time (in\%) that the bearing is in conducting state can be calculated per Equation (1). The measurement window $\left(t_{\text {Total }}\right)$ for each test is approximately $30 \mathrm{~s}$, and " $n$ " is the total number of breakdown events. The number of breakdowns per second are also shown for the measured point. The breakdowns are normalized per second to make comparisons between different tests.

$$
\mathrm{ToC}=\frac{\sum_{1}^{n}(\text { Pulse duration })}{t_{\text {Total }}}
$$

The resistance $R_{\mathrm{B}}$ is evaluated as the DC resistance of the bearing during conducting state from the ratio of bearing voltage and bearing current. The bearing voltage and the current through the bearing is recorded using a data acquisition card of type NI USB 6251. The data acquisition card offers a maximum aggregated sampling rate of $1 \mathrm{MS} / \mathrm{s}$. Since we use two channels, the sampling rate will be $500 \mathrm{kS} / \mathrm{s}$ per channel. The bearing resistance is calculated during every breakdown event. Since the variation could be large, $R_{\mathrm{B}}$ is presented in form of box plot to show the statistically significant values such as median, along with $75^{\text {th }}$ percentile and $25^{\text {th }}$ percentile of the data set which form the limits of the box.

2.4. Testing Procedure. The bearing was lubricated with a test oil sample and brought into rotation at the set operating parameter. During this start (Start 1), five measurements were conducted, where each measurement lasted for $30 \mathrm{~s}$. The rotating bearing was stopped for a duration of 2 minutes to save the accumulated data. Same procedure was followed for the second (Start 2) and the third start sequences (Start 3). Hence, ten to fifteen measurements were done with every lubricant sample. This procedure was adopted to investigate the effect of start-stops on the insulation breakdown in bearing.

\section{Results and Analyses}

The results are broadly classified into two sections: conduction pattern analysis due to particle-initiated breakdowns and bearing resistance during the breakdowns.

\subsection{Conduction Pattern Analysis}

3.1.1. Reference Measurements. Before main tests, reference measurements with clean, particle-free fresh oil sample were conducted. For this, the bearing was disassembled, cleaned from the corrosion inhibitor grease, reassembled and lubricated with particle-free fresh oil sample. For all the tests in this section, the bearing was run at fixed operating point. The bearing was run at a speed of $2000 \mathrm{rpm}$, and an axial load of $4 \mathrm{~N}$ was applied, resulting in a total calculated lubricant film thickness of $1.37 \mu \mathrm{m}$, at $20^{\circ} \mathrm{C}$. The film thickness between the inner and the balls is $0.58 \mu \mathrm{m}$, while between the outer ring and the ball is $0.75 \mu \mathrm{m}$.

For reference tests, no current activity was observed when $5 \mathrm{~V} \mathrm{DC}$ is applied to it. Hence the reference level for all the experiments is at $0 \% \mathrm{ToC}$, which refers to a bearing in fully 


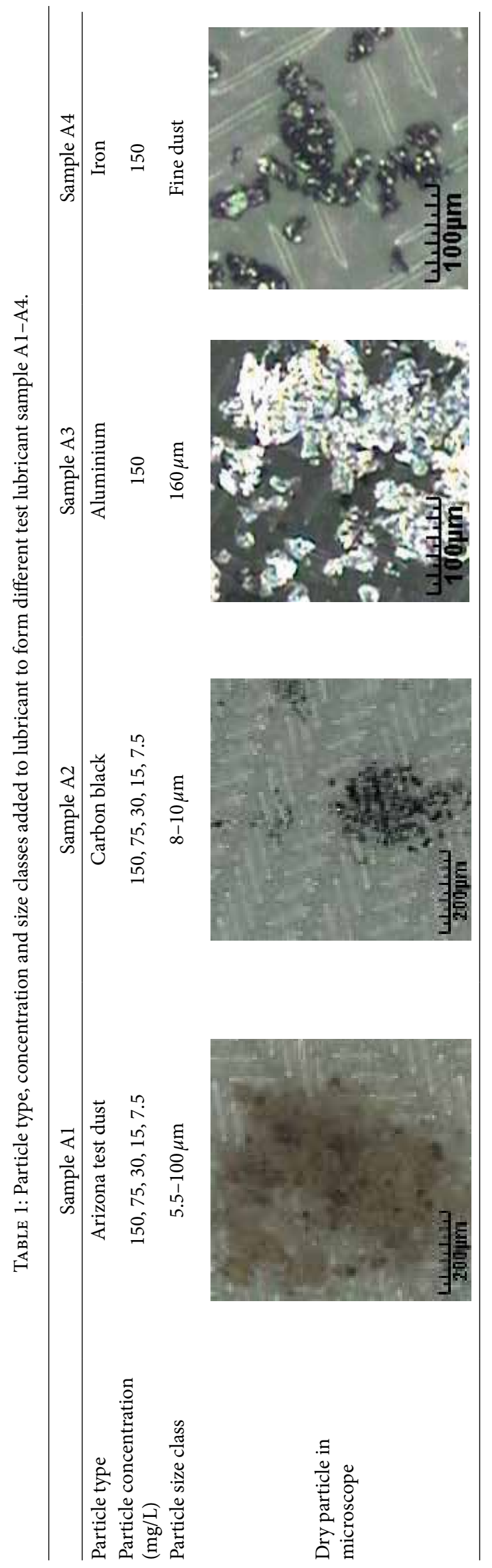




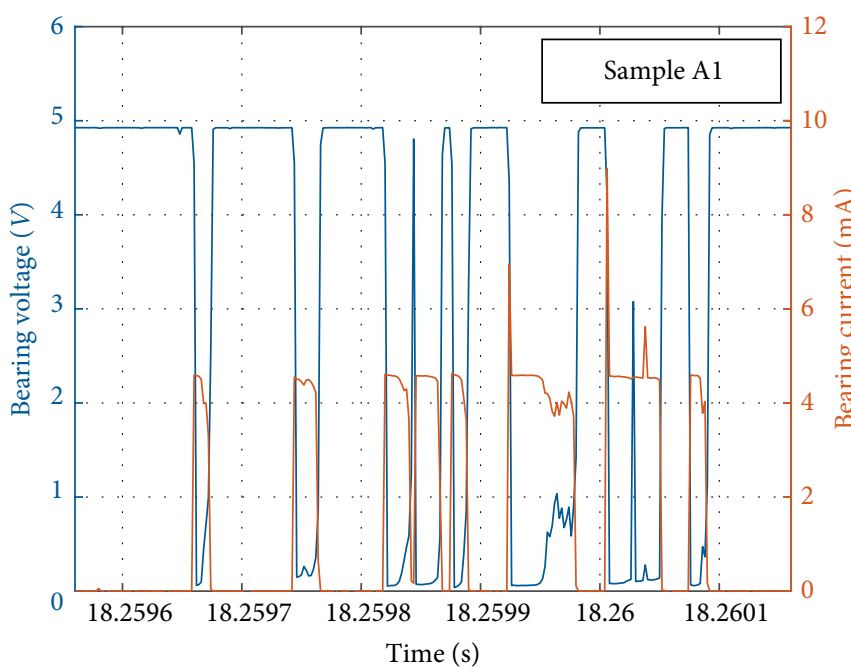

(a)

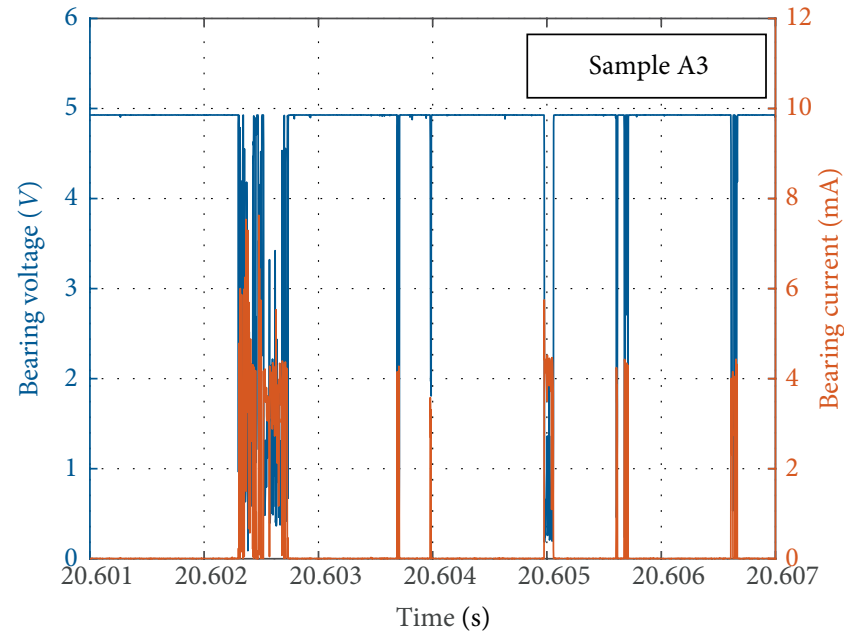

(c)

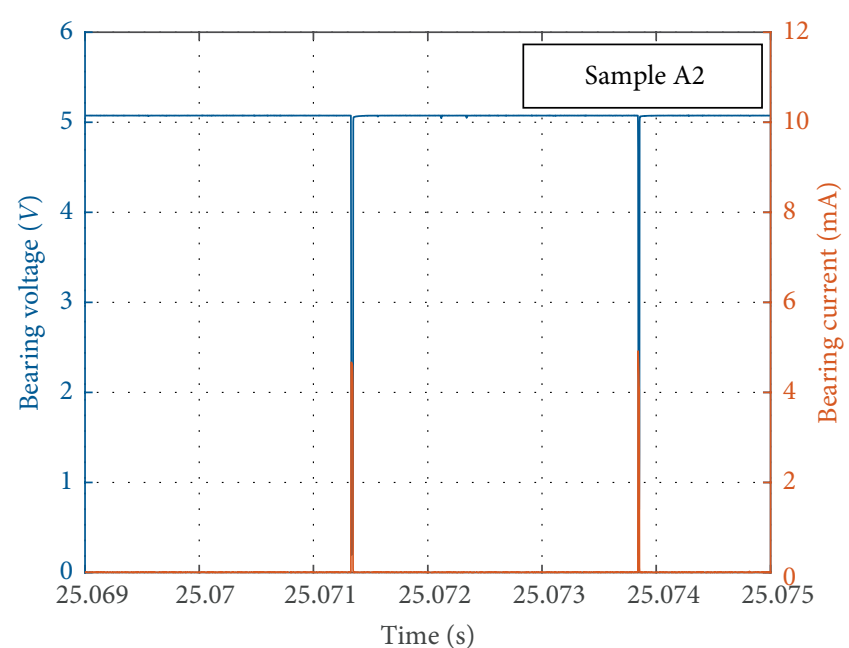

(b)

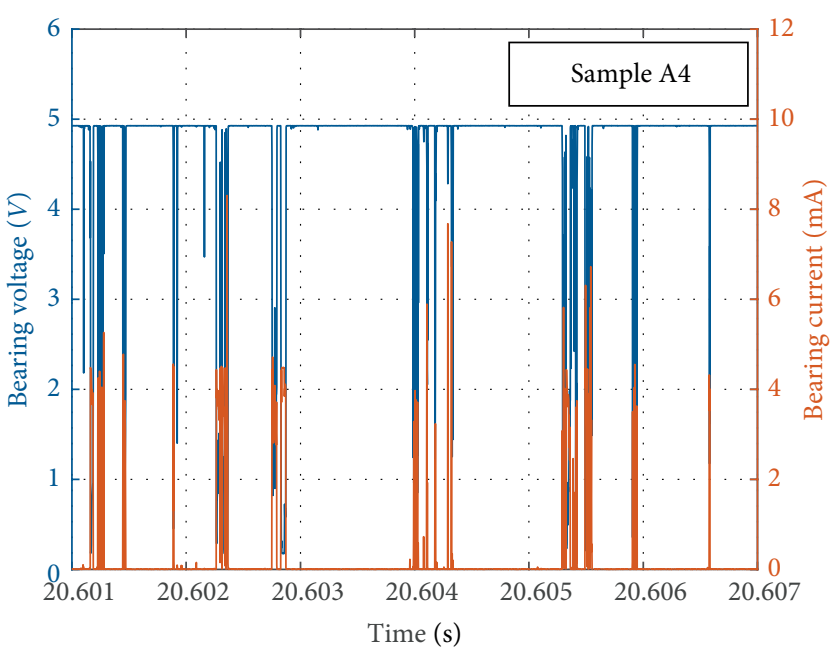

(d)

FIGURE 5: Bearing voltage (blue) and bearing activity (orange) for particle-initiated breakdowns due to different types of particles. The particle concentration is $150 \mathrm{mg} / \mathrm{L}$ and the measurement window shown is of $600 \mu \mathrm{s}$ for tests shown above.

insulating state. Thus, we can conclude that the bearing does not have asperity contact initiated breakdowns and voltage dependent breakdowns at these operating parameters. All breakdowns occurring will be only caused by particle-initiated three-body abrasion contacts, and the percentage time of conduction will be presented a function of particle concentration.

\subsubsection{Conduction Pattern Analysis due to Particle-Initiated}

Breakdowns. The particle-initiated breakdowns in the bearing are characteristically different according to the type of particle used for contamination. The bearing voltage and the current activity during breakdown event is shown in Figure 5. A breakdown event are characterized by a sudden drop in bearing voltage and passage of current for the duration of the breakdown event. A breakdown event is relatively longer for Sample A1 compared to other samples. The bearing voltage and the bearing current activity also fluctuate less compared to other samples. Current activity in Sample A2 is relatively less compared to other samples. The break down events showing bearing voltage and current due to different particles is shown in Figure 5.

The results of the tests with Sample A1 are grouped in two separate charts, first chart with particle-concentration of 75 and $150 \mathrm{mg} / \mathrm{L}$ and second with particle concentrations 30,15 , and $7.5 \mathrm{mg} / \mathrm{L}$ and lower since the current activity varies by an order of magnitude. At a particle concentration of $150 \mathrm{mg} / \mathrm{L}$, the number of breakdowns is in order of few 1000's per second, as shown in Figure 6. In Start 1, the mean value of breakdowns is 4722 per second. For Start 2, number of breakdowns reduce to a mean value of 2426 per second. The reduction in number of breakdowns is a direct result of lesser number of particle bridges forming between the inner and the outer raceway of the bearing. This also results in reduction in $\mathrm{ToC}$ from a mean value of $9.5 \%$ in Start 1 to a mean value of $4.4 \%$ in Start 2. At a lower particle concentration of $75 \mathrm{mg} / \mathrm{L}$, the mean value is 2287 per second in Start 1 and 1415 per second in Start 2.

For particle concentration of $30 \mathrm{mg} / \mathrm{L}$ and lower, the number of breakdowns per second are in few 100's per second accompanied with reduced ToC, shown in Figure 7. The 


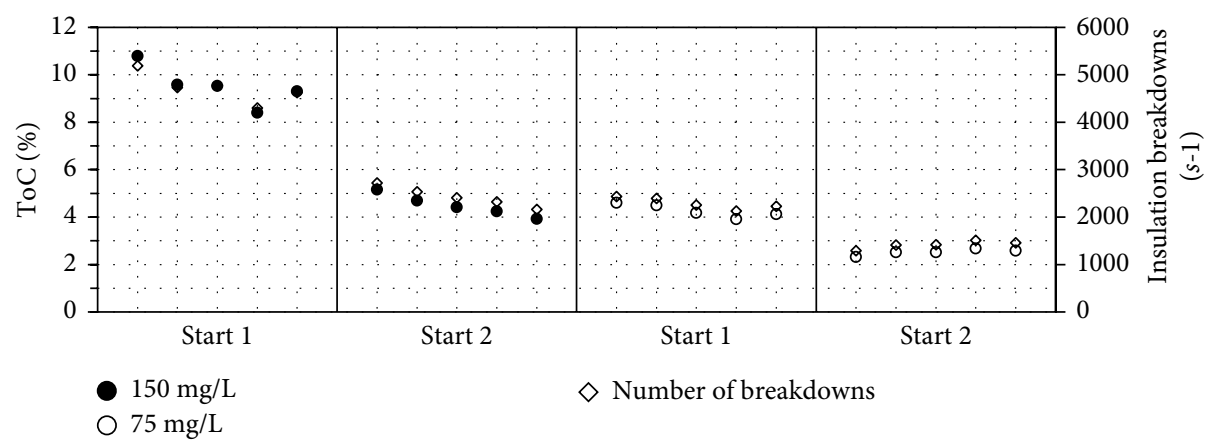

FIgURE 6: Particle-initiated breakdowns when the bearing is lubricated with Sample A1, with particle concentrations of $150 \mathrm{mg} / \mathrm{L}$ and $75 \mathrm{mg} / \mathrm{L}$. At a given concentration, the ToC in Start 2 reduces to approximately half the value of Start 1 . The number of breakdowns (per second) is shown on the secondary $y$-axis.

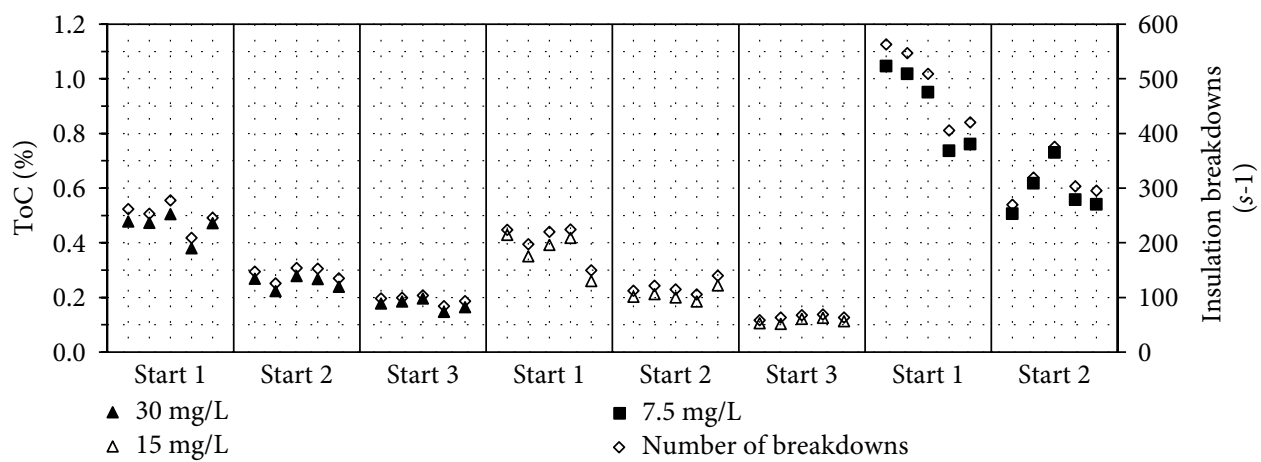

FIgure 7: Particle-initiated breakdowns in bearing lubricated Sample A1 mixed with different concentration of Arizona test dust varied at $30 \mathrm{mg} / \mathrm{L}, 15 \mathrm{mg} / \mathrm{L}$, and $7.5 \mathrm{mg} / \mathrm{L}$.

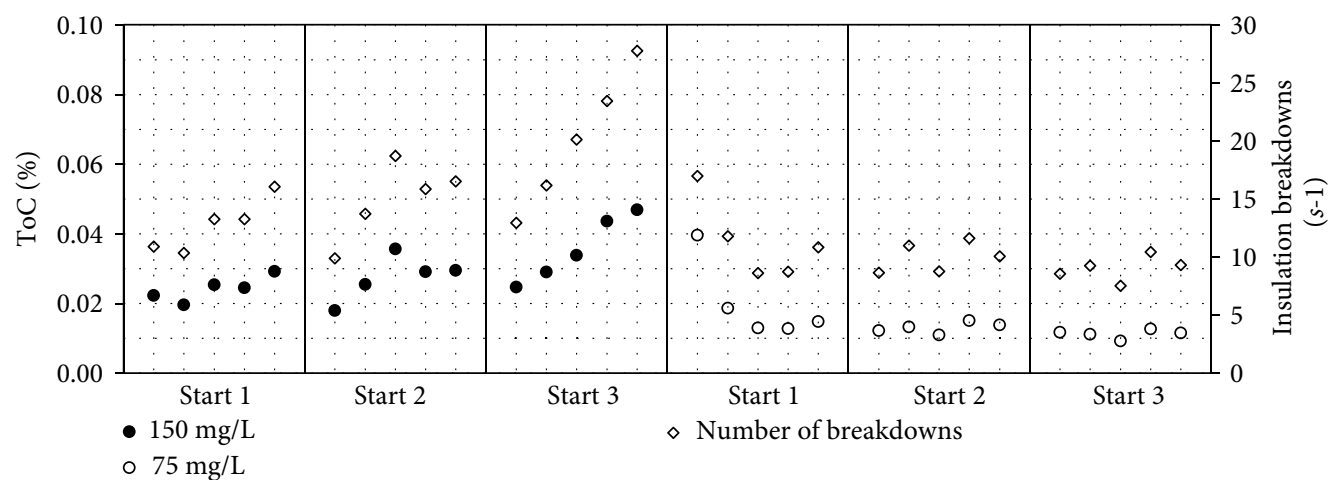

Figure 8: ToC due to carbon black particles of size $8-10 \mu \mathrm{m}$ at different concentration levels of $150 \mathrm{mg} / \mathrm{L}$ and $75 \mathrm{mg} / \mathrm{L}$.

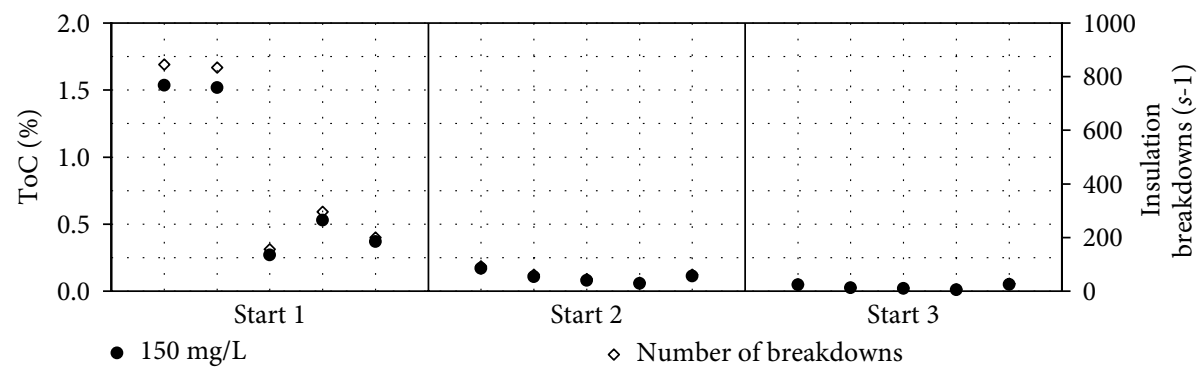

FIgURE 9: Percentage time of conduction for lubricant mixed with aluminium powder at concentration of $150 \mathrm{mg} / \mathrm{L}$. 


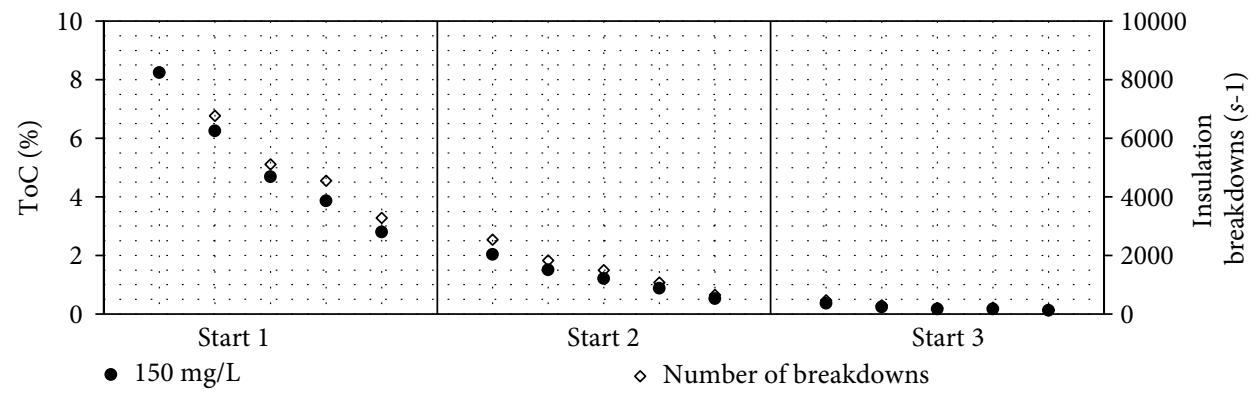

FIGURE 10: Percentage time of conduction for bearing lubricated with fine iron particles at a concentration of $150 \mathrm{mg} / \mathrm{L}$.
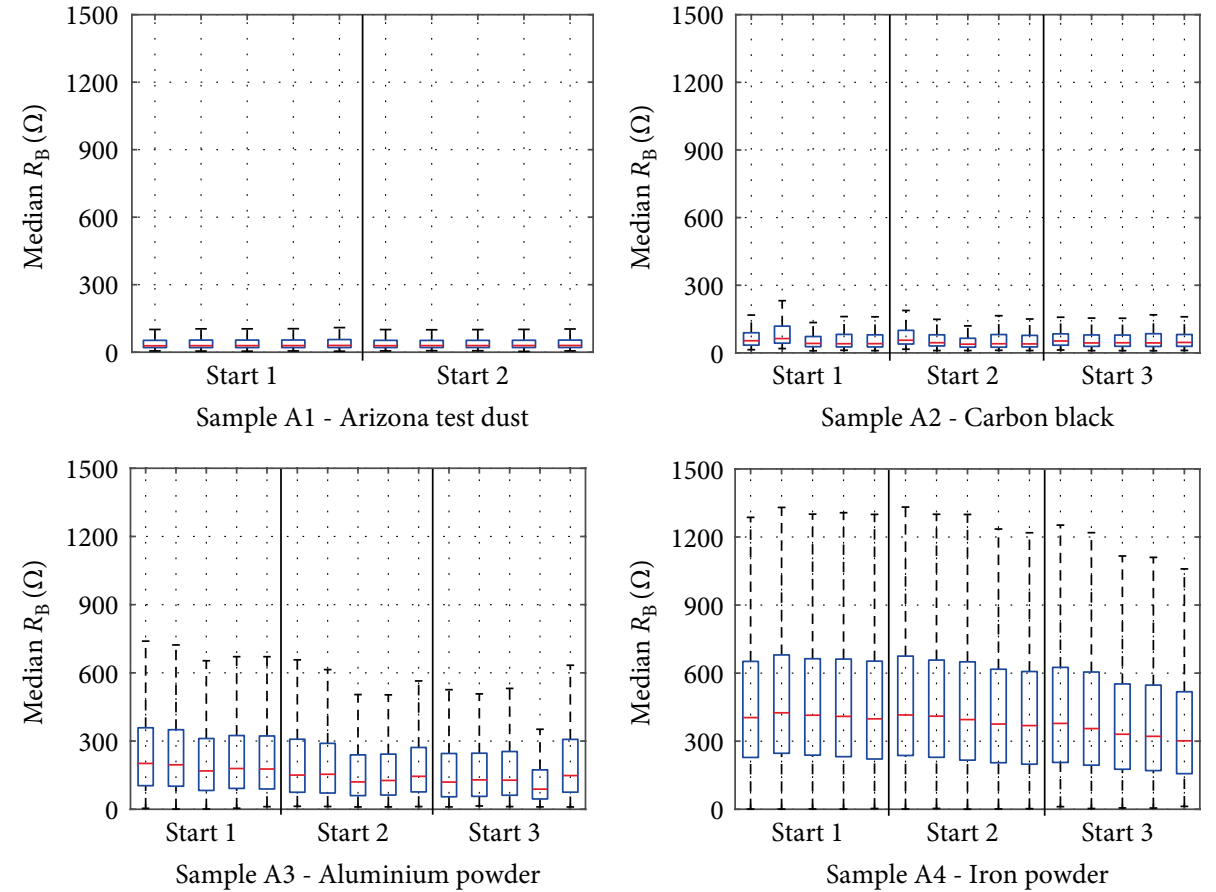

FIGURE 11: The value of $R_{B}$ for different particle types at a concentration level of $150 \mathrm{mg} / \mathrm{L}$. The median value of $R_{\mathrm{B}}$ fluctuates significantly for Sample A3 and A4, while it is relatively stable for Sample A1 and A2.

reduction in breakdowns and $\mathrm{ToC}$ is due to removal of the particles from the load zone, and into the oil bath, and settling at the bottom of the sump due to gravitational force.

For tests with Sample A2, at a particle concentration of $150 \mathrm{mg} / \mathrm{L}$, the breakdowns are significantly lower than Sample A1. The bearing has on an average of 16 breakdowns per second, corresponding to ToC of $0.03 \%$, (Figure 8 ). The number of breakdowns in Start 2 and Start 3 are higher compared to Start 1 , and can be credited to the small size of the carbon black particles in conjunction with the ability to store charge on their surfaces, thus they could agglomerate on air bubbles. At $75 \mathrm{mg} / \mathrm{L}$, the ToC and breakdowns are reduced to half, and are shown in Figure 8. A particle concentration of $30 \mathrm{mg} / \mathrm{L}$ and lower results in less than 10 breakdowns per second, which corresponds to less than $0.01 \%$ ToC. These results are not displayed due to space constraints.

For tests with Sample A3, the insulation breakdowns recorded ranges up to few 100's per second, but the number reduces significantly in Start 1, (Figure 9). The breakdowns in the bearing are initially around 830 per second, but they reduce to less than 300 per second in the last three tests. Correspondingly, the ToC is around $1.5 \%$ for the first two measurements in Start 1, but reduced to about $0.5 \%$ in the last three measurements. This indicates quick removal of large sized particles from the bearing during operation. After stopping and measuring for Start 2 , the mean value of ToC for five measurements is $0.1 \%$, while it reduces to a mean value of $0.03 \%$ in Start 3. During Start 2 and Start 3, the breakdowns also reduced to less than 100 per second.

For tests with Sample A4, has breakdowns similar to Sample A1, but the decay in current activity is must faster. The ToC is $8.24 \%$ at the first measurement in Test 1 resulting from 8258 breakdowns per second. The value subsequently drops to $2.8 \%$ (from 3278 breakdowns per second) in the fifth test of Start 1, indicating to a drop of number of iron particles in the loaded zone in Start 1. The trend continues in Start 2 and Start 3 , and can be seen in Figure 10. During the tests, it is interesting to notice that $\mathrm{ToC}$ systematically reduces with each 

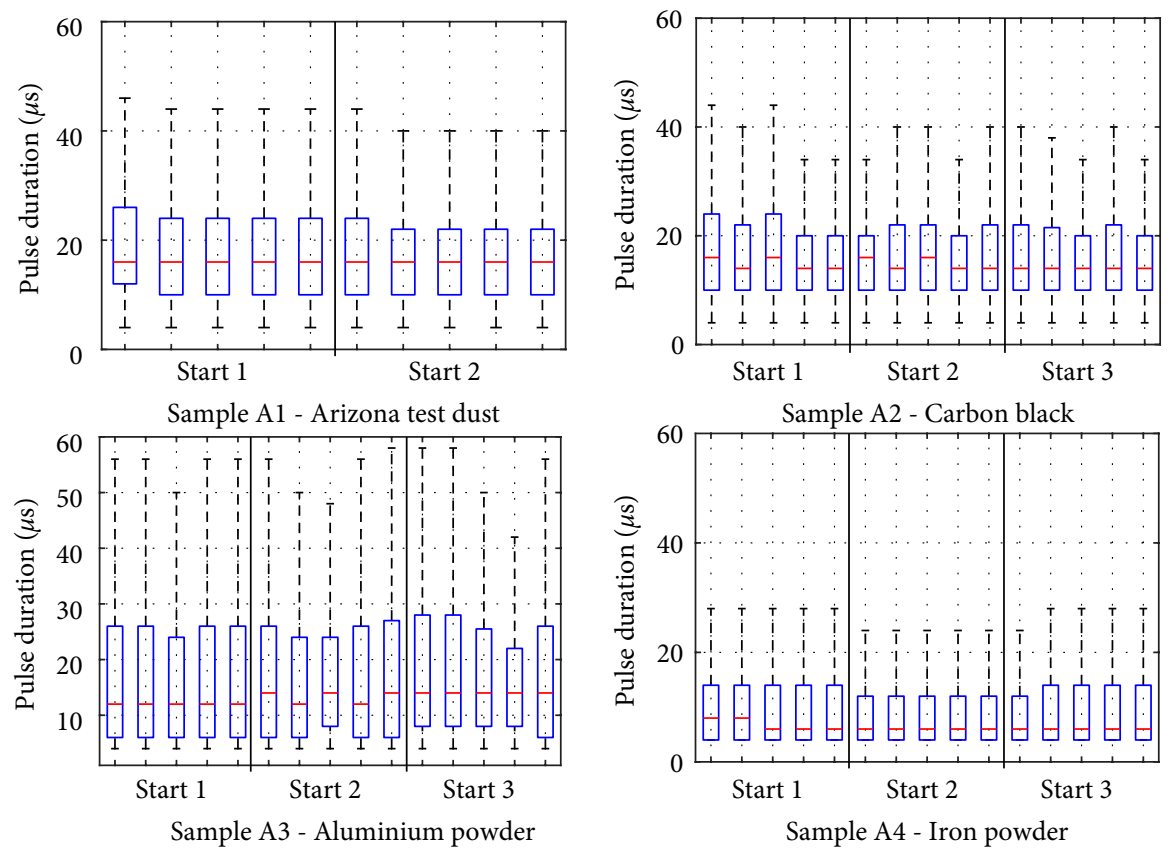

FIGURE 12: Median values of pulse duration during insulation breakdowns caused by different types of particles, at a fixed concentration of $150 \mathrm{mg} / \mathrm{L}$.

measurement, along with the number of particle-initiated breakdowns per second. This indicates that these harder metallic particles undergo abrasion during operation and crumble in to smaller fragments due to fracture. It is seen from these measurements that the current activity is highest for Sample A1, followed by Sample A4, Sample A3 and Sample A2.

\subsection{Evaluation of Equivalent Bearing Resistance $\left(R_{\mathrm{B}}\right)$ in} Conducting State. A breakdown mechanism will result in a low resistance path, resulting in discharge of voltage and energy that are in parallel with the bearing, or when bearing is a part of a HF circulating current path. The low resistance path is offered by particles bridging the inner and outer raceway of the bearing. When the insulating properties of the bearing breaks down, there will be remaining resistance in path of the flow of current, which is a measure of $R_{\mathrm{B}}$. Depending on the type of particle, the mean value of $R_{\mathrm{B}}$ during a single discharge event can vary significantly, shown in Figure 11. Analyses of $R_{\mathrm{B}}$ for different particles at a fixed concentration level of $150 \mathrm{mg} / \mathrm{L}$ show that the median value ranges between $28 \Omega$ and $63 \Omega$ in case of Sample A1 and A2, while it is about 5-10 times higher for samples A3 and A4, Figure 11.

For Sample A1, the median value of $R_{\mathrm{B}}$ remains at $28 \Omega$ for all tests, while it relatively varies more for the other types of particles, as shown in Figure 12.

The measured data has the $75^{\text {th }}$ and the $25^{\text {th }}$ percentile values at $54 \Omega$ and $20 \Omega$ for Sample A1. The measured $R_{\mathrm{B}}$ remains rather constant, and does not change with the number of starts of the bearing, and the test sequence. For Sample A1, minimum value reached by $R_{\mathrm{B}}$ is found to have a median value of $17 \Omega$ in these tests, while the smallest value that $R_{\mathrm{B}}$ could reach less than $1 \Omega$ and could be a due to larger contact during breakdown event. Median values of $R_{\mathrm{B}}$ are not affected by the concentration level of a type of particle, but rather by its size.
The median values pulse duration stays approximately in the same order of magnitude for all different types of particles, but large spread is seen with Sample A3 that could be an effect of large sized particles.

Analyses of duration of discharges show that different particles appeared to cause the breakdown events for more or less for the same duration. This could be due to fix rotational speed of the bearing for different tests. The $75^{\text {th }}$ percentile value of the measured pulse duration ranged up to $30 \mu \mathrm{s}$, while maximum values could reach up to $60 \mu \mathrm{s}$ in case of aluminium powder. The aluminium powder particles were larger than all other particles tested, and hence stayed longer in the load zone until they fracture into smaller particles. The fine iron powder in Sample A4 are much smaller than aluminium powder and hence results in lower values of pulse duration during the breakdowns.

\section{Conclusions}

To establish a further understanding of electrical properties of a miniature bearing when exposed to a shaft voltage, an electric circuit model is proposed. The parameters associated with the two proposed electrical states are discussed and in this paper, the breakdown characteristics due to particles of different type, size, and concentrations is presented.

A breakdown of the bearing insulation requires the presence of an active mechanism that initiates the breakdown and a voltage source that drives the current through the bearing during the insulation breakdown.

It is concluded from these measurements that the current activity is highest for ATD, followed by iron powder, aluminium powder and carbon black particles. The current threshold limit of $150 \mathrm{mg} / \mathrm{L}$ for cleanliness levels in gear box oils in wind 
turbines is recommended to be lowered to $30 \mathrm{mg} / \mathrm{L}$ as the time of conduction is reduced by one order of magnitude.

Breakdowns initiated due to Arizona test dust reduce gradually during a given start, but the amount of particle bridges halve as the rotation of the bearing is stopped momentarily. The breakdowns also reduce to approximately to half in successive starts. On reduction of particle concentration level by 10 times, from $150 \mathrm{mg} / \mathrm{L}$ to $15 \mathrm{mg} / \mathrm{L}$; the mean value of number of breakdowns reduce from 4722 per second to merely 203 per second in Start 1. During Start 2, the number of breakdown reduce to approximately half in both the cases.

Breakdowns initiated due to Carbon black particles are much shorter and much less compared to the Arizona test dust. This is credited to smaller size, possibly leading to their inability to form complete conducting bridges between the ball and the inner and outer raceways of the bearing. The discharges are 100 times lower than Arizona test dust particles, and the breakdowns are below 30 per second.

For Aluminum powder and fine iron powder, the number of breakdowns gradually reduces to a lower value as the tests are run. This indicates that these harder metallic particles undergo abrasion during operation and crumble in to smaller fragments due to fracture.

During a single particle-initiated breakdown event, the instantaneous value of $R_{\mathrm{B}}$ varies significantly, and can vary up to several 100's of ohms. This can be attributed to contact resistance offered by a multi-body contacts. The median value of $R_{\mathrm{B}}$ ranges between $28 \Omega$ and $63 \Omega$ in case of Sample A1 and A2, while it is about 5-10 times higher for samples A3 and A4. For Sample A1, minimum value reached by $R_{\mathrm{B}}$ is found to have a median value of $17 \Omega$ in these tests, while the smallest value that $R_{\mathrm{B}}$ could reach less than $1 \Omega$ and could be a due to larger contact during breakdown event. The duration of discharge is approximately same for all the particles, and could be attributed to fixed speed during the experiments.

\section{Data Availability}

The breakdown data used to support the findings of this study are available from the corresponding author upon request.

\section{Conflicts of Interest}

The authors declare that they have no conflicts of interest.

\section{Acknowledgments}

This publication is partially based on the doctoral thesis of Dr. Abhishek Joshi. This project is financed through the Swedish Wind Power Technology Centre (SWPTC). SWPTC is a research center for design of wind turbines. The purpose of the center is to support Swedish industry with knowledge of design techniques as well as maintenance in the field of wind power. The Centre is funded by the Swedish Energy Agency, Chalmers University of Technology as well as academic and industrial partners. The authors would like to thank Olle Bankeström of SKF Gothenburg for providing test samples, lab facilities, analyses and correspondence in the research project.

\section{References}

[1] K. Alewine and W. Chen, "A review of electrical winding failures in wind turbine generators," in Electrical Insulation Conference (EIC), IEEE, 2011.

[2] K. Alewine, "Understanding wind turbine generator failures-modes and occurances," An update Wind Project O\&M and Safety Seminar, 17 pages, 2014.

[3] O. V. Thorsen and M. Dalva, "A survey of faults on induction motors in offshore oil industry, petrochemical industry, gas terminals, and oil refineries," IEEE Transactions on Industrial Electronics, vol. 31, no. 5, pp. 1186-1196, 1995.

[4] A. H. Bonnett, "Root cause failure analysis for AC induction motors in the petroleum and chemical industry," in 57th Annual Petroleum and Chemical Industry Conference (PCIC), IEEE, San Antonio, TX, USA, 2010.

[5] P. Tavner, Offshore Wind Turbines: Reliability, Availability and Maintenance, Institution of Engineering and Technology, 2012.

[6] J. Zitzelsberger, W. Hofmann, A. Wiese, and P. Stupin, "Bearing currents in doubly-fed induction generators," in European Conference on Power Electronics and Applications, IEEE, Dresden, Germany, 2005.

[7] A. Muetze, Bearing Currents in Inverter-Fed AC Motors, Darmstadt University of Technology, Darmstadt, Germany, 2003.

[8] A. Muetze and A. Binder, "Systematic approach to bearing current evaluation in variable speed drive systems," European Transactions on Electrical Power, vol. 15, no. 3, pp. 217-227, 2005.

[9] S. Chen and T. A. Lipo, "Bearing current, EMI and soft switching in induction motor drives: a systematic analysis, design and evaluation," The University of Wisconsin, Madison: Ann Arbor, pp. 234-234, 1995.

[10] V. Hausberg and H. O. Seinsch, "Capacitively induced voltages and currents in converter fed induction machines," Electrical Engineering, vol. 82, no. 3-4, pp. 153-162, 2000.

[11] M. Cacciato, A. Consoli, L. Finocchiaro, and A. Testa, "High frequency modeling of bearing currents and shaft voltage on electrical motors," in Proceedings of the Eighth International Conference on Electrical Machines and Systems (ICEMS), IEEE, Nanjing, China, 2005.

[12] M. Kriese, E. Wittek, S. Gattermann, H. Tischmacher, G. Poll, and B. Ponick, "Prediction of motor bearing currents for converter operation," in The XIX IEEE International Conference on Electrical Machines (ICEM), IEEE, Rome, Italy, 2010.

[13] D. Busse, J. Erdman, R. Kerkman, D. Schlegel, and G. Skibinski, "Characteristics of shaft voltage and bearing currents," IEEE Industry Applications Magazine, vol. 3, no. 6, pp. 21-32, 1997.

[14] A. Muetze and A. Binder, "Techniques for measurement of parameters related to inverter-induced bearing currents," IEEE Transactions on Industrial Electronics, vol. 43, no. 5, pp. 1274-1283, 2007.

[15] S. Guttowski, S. Weber, M. Schinkel, W. John, and H. Reichl, "Troubleshooting and fixing of inverter driven induction motor bearing currents in existing plants of large size-an evaluation of possible mitigation techniques in practical applications," in Twenty-First Annual IEEE Applied Power Electronics Conference and Exposition, 2006. APEC '06, IEEE Dallas, TX, USA, 2006.

[16] A. Muetze and A. Binder, "Experimental evaluation of mitigation techniques for bearing currents in inverter-supplied drivesystems-investigations on induction motors up to $500 \mathrm{~kW}$," 
in IEEE International Electric Machines and Drives Conference, IEMDC'03, IEEE, Madison, WI, USA, 2003.

[17] R. Smolenski, A. Kempski, and J. Bojarski, "Statistical approach to discharge bearing currents," COMPEL - The International Journal For Computation and Mathematics in Electrical and Electronic Engineering, vol. 29, no. 3, pp. 647-666, 2010.

[18] T. A. Lipo, S. Chen, and D. W. Novotny, Circulating Type of Motor Bearing Currents in Inverter Drives, University of WisconsinMadison, Madison, Wisconsin, 1996.

[19] V. Niskanen, A. Muetze, and J. Ahola, "Study on bearing impedance properties at several hundred kilohertz for different electric machine operating parameters," IEEE Transactions on Industrial Applications, vol. 50, no. 5, pp. 3438-3447, 2014.

[20] A. Muetze and A. Binder, "Practical rules for assessment of inverter-induced bearing currents in inverter-fed ac motors up to $500 \mathrm{kw}$, IEEE Transactions on Industrial Electronics, vol. 54, no. 3, pp. 1614-1622, 2007.

[21] A. M. Garcia, D. G. Holmes, and T. A. Lipo, "Reduction of bearing currents in doubly fed induction generators," in Conference Record of the 2006 IEEE Industry Applications Conference Forty-First IAS Annual Meeting, IEEE, Tampa, FL, USA, 2006.

[22] M. Whittle, J. Trevelyan, and P. J. Tavner, "Bearing currents in wind turbine generators," Journal of Renewable and Sustainable Energy, vol. 5, no. 5, 053128 pages, 2013.

[23] Y. Gemeinder, M. Schuster, B. Radnai, B. Sauer, and A. Binder, "Calculation and validation of a bearing impedance model for ball bearings and the influence on EDM-currents," in 2014 International Conference on Electrical Machines (ICEM), IEEE, pp. 1804-1810, Berlin, Germany, 2014.

[24] B. J. Hamrock, S. R. Schmid, and B. O. Jacobson, Fundamentals of Fluid Film Lubrication, NASA Reference Publication. 1991: National Aeronautics and Space Administration, Scientific and Technical Information Office, 2004.

[25] A. Beroual, C. Marteau, and R. Tobazeon, "Behavior of streamers in liquids under step voltages in point-plane geometry," IEEE Transactions on Electrical Insulation, vol. 23, no. 6, pp. 955-959, 1988.

[26] M. Butcher, A. A. Neuber, M. D. Cevallos, J. C. Dickens, and H. Krompholz, "Conduction and breakdown mechanismsin transformer oil," IEEE Transactions on Plasma Science, vol. 34, no. 2, pp. 467-475, 2006.

[27] W. G. Chadband, "A pre-breakdown phenomenon in liquid dielectrics," British Journal of Applied Physics, vol. 16, no. 3, pp. 305-313, 1965.

[28] W. G. Chadband, "From bubbles to breakdown, or vice-versa," in IEEE International conference on conduction and breakdown in dielectric liquids(ICDL), IEEE, Baden-Dattwil, Switzerland, 1993.

[29] J. C. Devins, S. J. Rzad, and R. J. Schwabe, "Breakdown and prebreakdown phenomena in liquids," Journal of Applied Physics, vol. 52, no. 7, pp. 4531-4545, 1981.

[30] J. Qian, R. P Joshi, J. Kolb et al., "Microbubble-based model analysis of liquid breakdown initiation by a submicrosecond pulse," Journal of Applied Physics, vol. 97, no. 11, pp. 113304-113310, 2005.

[31] A. A. Zaky, A. Nosseir, I. Y Megahed, and C. Evangelou, "Electrical breakdown of mineral oil under non-uniform fields," Journal of Physics D: Applied Physics, vol. 9, no. 15, pp. 2287-2293, 1976.
[32] M. Alsaad, S. Bair, D. M. Sanborn, and W. O. Winer, "Glass transitions in lubricants: its relation to elastohydrodynamic lubrication (EHD)," Journal of Lubrication Technology, vol. 100, no. 3, pp. 404-416, 1978.

[33] S. Bair, "The viscosity at the glass transition of a liquid lubricant," Friction, vol. 7, no. 1, pp. 86-91, 2019.

[34] M. A. Alsaad, W. O. Winer, F. D Medina, and D. C. O'Shea, "Light-scattering study of the glass transition in lubricants," Journal of Lubrication Technology, vol. 100, no. 3, pp. 418-422, 1978.

[35] J. M. H. Ukonsaari, Oil Cleanliness in Wind Turbine Gearboxes, 2012.

[36] B. O. Jacobson, Ed., "Chapter 21 Lubricant contamination," Tribology Series, Elsevier, pp. 341-356, 1991.

[37] J. H. Adair, J. J. Mecholsky, and D. J. Jr Mitchell, "Effects of particulate debris morphology on the rolling wear behavior of all-steel and si3n4-steel bearing element couples," in Annual Cocoa Beach Conference and Exposition, Oak Ridge National Lab, TN (US), p. 12, Cocoa Beach, FL (US), 1999.

[38] Rob, "Analyzing contaminants, stains and debris-Part 2," 2010, http://failure-analysis.info/2010/07/analyzing-contaminantsstains-and-debris-part-2/.

[39] J. Zhu, J. M. Yoon, D. He, and E. Bechhoefer, "Online particlecontaminated lubrication oil condition monitoring and remaining useful life prediction for wind turbines," Wind Energy, vol. 18, no. 6, pp. 1131-1149, 2015.

[40] D. D. DiBitonto, P. T. Eubank, M. R. Patel, and M. A. Barrufet, "Theoretical models of the electrical discharge machining process. I. A simple cathode erosion model," Journal of Applied Physics, vol. 66, no. 9, pp. 4095-4103, 1989.

[41] J. M. Erdman, R. J. Kerkman, D. W. Schlegel, and G. L. Skibinski, "Effect of PWM inverters on AC motor bearing currents and shaft voltages," IEEE Transactions on Industry Applications, vol. 32, no. 2, pp. 250-259, 1996.

[42] M. R. Patel, M. A. Barrufet, P. T. Eubank, and D. D. DiBitonto, "Theoretical models of the electrical discharge machining process. II. The anode erosion model," Journal of Applied Physics, vol. 66, no. 9, pp. 4104-4111, 1989.

[43] H. Prashad, "Appearance of craters on track surface of rolling element bearings by spark erosion," Tribology International, vol. 34 , no. 1, pp. 39-47, 2001.

[44] P. Mäki-Ontto, Modeling and reduction of shaft voltages in AC motors fed by frequency converters, Helsinki University of Technology, Espoo, Finland, 2006.

[45] M. Edvall, "Experimental study of current damages in bearings," in Proceedings of the Third International Conference on Advances in Processing, Testing and Application of Dielectric Materials, pp. 141-146, 2007.

[46] O. Schenk, "Current passage through rolling bearings," SKF Kugellagerfabriken, 1955.

[47] A. Joshi, "Electrical characterisations of bearings, in department of electrical engineering," Chalmers University of Technology, Gothenburg, Sweden, 188 pages, 2019.

[48] D. Busse, J. Erdman, R. J. Kerkman, D. Schlegel, and G. Skibinski, "System electrical parameters and their effects on bearing currents," IEEE Transactions on Industrial Applications, vol. 33, no. 2, pp. 577-584, 1997.

[49] Shell, "Shell Turbo Oils T," 2015. 

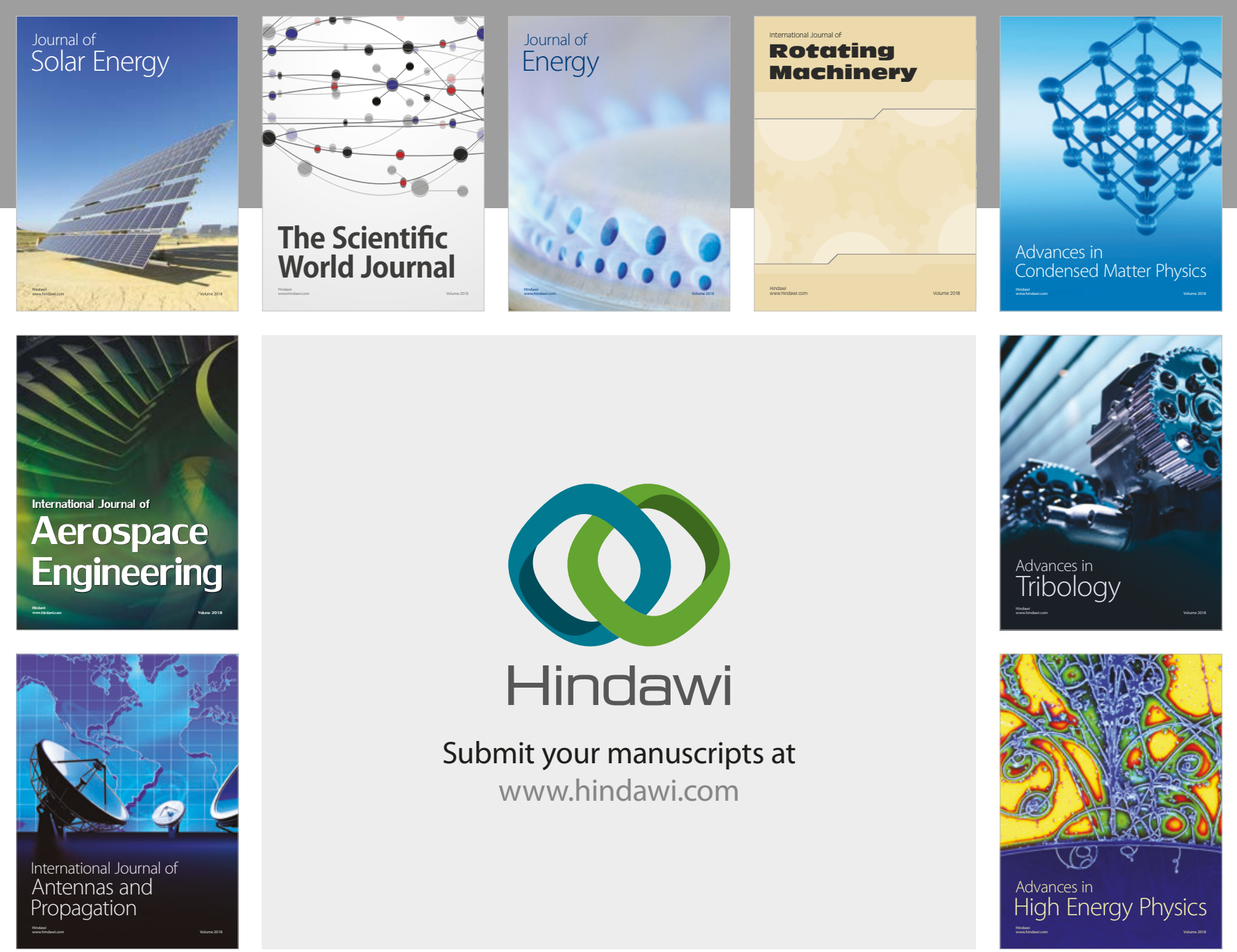

Submit your manuscripts at

www.hindawi.com
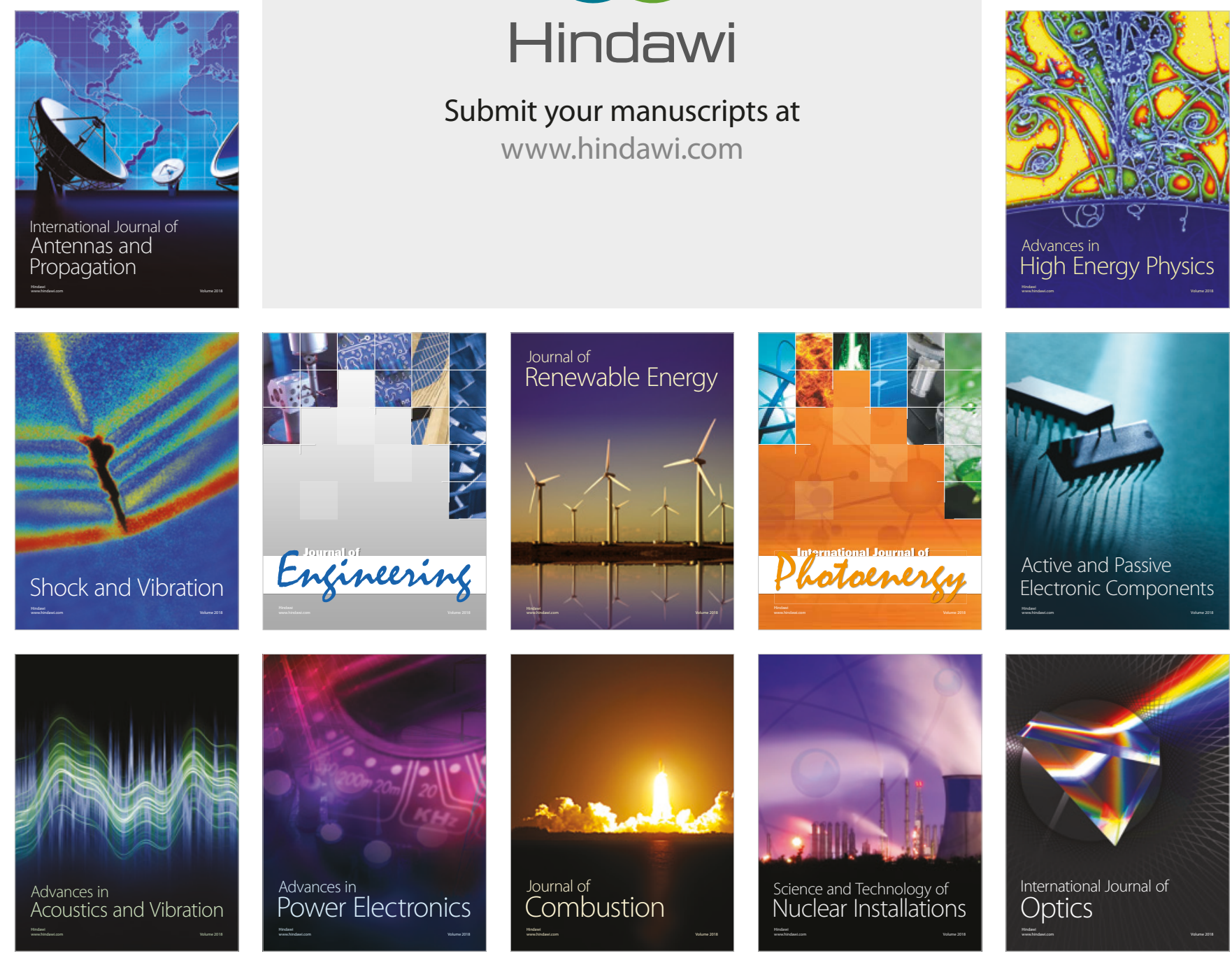